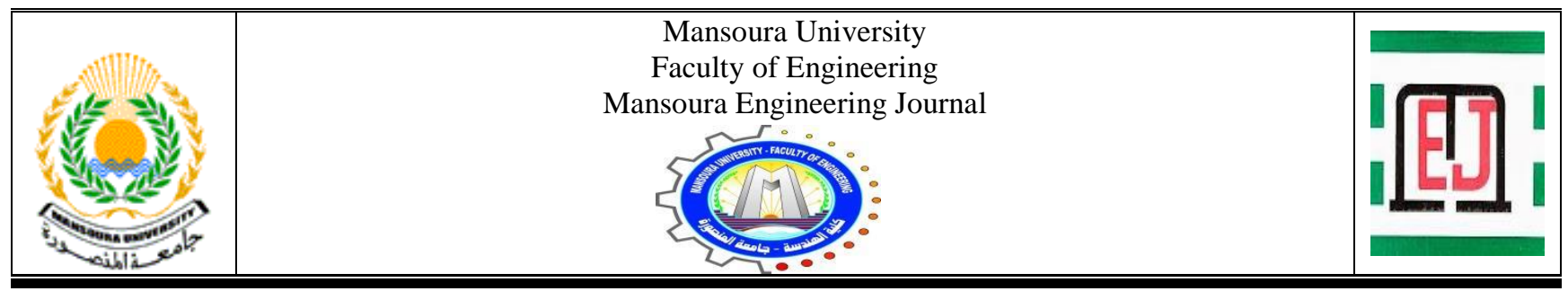

\title{
Advanced Grid Connected Solar Variable Speed Drive for Three Phase Asynchronous Motors
}

\author{
Ahmed M. Ismaiel*, Basem E. Elnaghi and Reham H.Mohammed
}

\begin{tabular}{|lr|}
\hline KEYWORDS: & \\
Solar & powered \\
Asynchronous & motor, \\
MPPT, & FOC, \\
Incremental & \\
Conductance, & \\
Photovoltaic Panels \\
\end{tabular}

\begin{abstract}
In this work, solar energy is used efficiently by running photovoltaic (PV) panels at their maximum power point (MPP) to power an asynchronous motor. Such methods are extremely beneficial in situations where other sources, such as grid electricity and other renewable sources, are limited. These asynchronous motors are more cost effective since they require less maintenance and operation cost. The primary elements of solar-powered Asynchronous motor system are the solar panel, control board, and motor set. The suggested system utilizes Asynchronous motor drive to provide power from solar energy to a motor by converting the DC electric power supplied by a PV array to AC electric power using an inverter. A solar panel with a power producing capacity of $5 \mathrm{~kW}$ is employed in the proposed work. The asynchronous motor utilized has a power rating of 4.5 HP. Three control techniques are used in this research Carrier based Pulse Width Modulation (PWM), Field Oriented Control (FOC), and Maximum Power Point Tracking (MPPT). This paper discusses computational demonstrating technique of MPPT like Incremental Conductance (Inc.) with Field Oriented Control Drive and compare it to the existing model of Perturb \& observe with Field Oriented Technique. The control techniques are demonstrated by using Matlab/Simulink. The simulation results show that the controllers based on Incremental Conductance methods with Field Oriented Control are more effective for each performance index because they have a smaller overshoot value, a shorter rising time, and a high dynamic response.
\end{abstract}

\section{List OF AbBREViations}

Received: (10 August, 2021) - Revised: (17 October, 2021) - Accepted: (20 October, 2021)

*Corresponding Author: Ahmed M. Ismaiel, Teaching Assistant in the Electrical Engineering Department, Suez Canal University, Ismailia, Egypt, (email: ahmed123ismaiel@gmail.com).

Basem E. Elnaghi, Associate Professor in the Electrical Engineering Department, Suez Canal University, Ismailia, Egypt, (email: Basem_elhady@eng.suez.edu.eg).

Reham H. Mohamed, Assistant Professor in the Electrical Engineering Department, Suez Canal University, Ismailia, Egypt, (email: Riry4mody@yahoo.com).

$I_{q_{s}}:$ Torque current component

$I_{d s}$ : Flux current component

$\psi_{R}$ : Rotor Flux

$T_{e}^{*}$ : Reference Torque

$\omega^{*}$ : Desired speed

$T_{r} \quad$ : Time constant

$L_{m}$ : Mutual inductance

$\theta_{f} \quad$ : Rotor flux position

$\theta_{r} \quad$ : Slip angle

$\theta_{m}$ : Rotor angle 


\section{INTRODUCTION}

I n 2011, According to the International Energy Agency, solar energy technology will have a major influence on its long-term advantages which is extensively distributed across the world since it is a clean, inexhaustible, self-sufficient resource, and its development is inexpensive because it is environment friendly, thereby benefiting mankind [1]. Photovoltaic powered motors have experienced considerable attention in solar energy technologies. PV powered motors use DC motor in many places in the world [2]. As mentioned in different literatures [3],[5], photovoltaic (PV) technology has several benefits. When compared to other non-ordinary vitality sources, the advantages of a sun-oriented PV reference frame are as follows: it retains the continuously enduring sun-powered vitality at no cost, it is eco-friendly without causing any kind of pollution in the environment, and It provides a low-noise operation and minimal support. The sun-powered PV module straightforwardly transforms the sun vitality into DC electric power. Using power molding technologies, the produced DC electric power is subsequently converted to the desired frame. The power molding unit includes a converter or inverter, depending on the application. Because of the government's sponsorship, the use of solarpowered motors has grown. The government's support lowered the cost of photovoltaic solar panels. Various approaches have been explored in the past to increase the performance of solar pumps [23-24]. Electrical array reconfiguration techniques were utilized. The used controller provides a simplified solution by providing a wide range of irradiance levels for supplying enough current to start the motor [6]. PV-fed DC motors have previously been used to power the pumping system. DC motor control methods are quite simple. By utilizing the most maximum power point tracking technique, the highest power can be obtained from the PV solar array [7]. However, asynchronous motors are gradually replacing DC motors since they have numerous benefits over DC motors, such as the proximity of the brushes and commutator, and are less dependable. The system in this case is to provide power to an asynchronous motor drive by converting the DC electric power supplied by the PV panels to AC power using an inverter. The output power taken from the inverter is given to the Asynchronous motor. It is always preferred that the PV panels operate at their maximum power point (MPP), which allows the PV electricity to be used efficiently [8-9]. The voltage source inverter (VSI) is used in control preparation applications such as static compensators, $\mathrm{AC}$ motor drives, and dynamic front end converters. In AC motor drives application, variable voltage and variable recurrence are necessary to control the motor speed. VSI is employed in power processing applications including AC motor drives, static compensators, and active front end converters. Variable frequency and variable voltage are necessary in the use of $\mathrm{AC}$ motor drives to regulate the motor speed. The DC link voltage feeding the inverter is fixed. PWM waveforms for a voltage source inverter may be produced by contrasting three-stage adjustment signals. and a typical triangular bearer (triangle-examination strategy) [13-16]. Alternatively, the space vector method might be used to generate PWM. The information of the rotor transition position edge in relation to the stator is the key to FieldOriented Control. It is conceivable to register the edge from shaft position data, given that other motor parameters are known. This methodology is currently presented by large name "Field Oriented Control" (FOC) [17]. Instead of the three-phase currents that are normally given to an asynchronous motor, two perpendicular currents can be used to control it. These two perpendicular currents called quadrature current $\left(i_{q}\right)$ and direct current $\left(i_{d}\right)$ are in charge of controlling torque component and flux component respectively in the motor.

\section{LITERATURE REVIEW}

A significant amount of researches have been conducted on PV solar energy, Asynchronous motor speed drive, pumping applications, and so on. This section has given some of the closely connected studies.

\section{A. Dead-Time Effect on Inverter Characteristics}

The study provided by $\mathrm{N}$ Urasaki et al. [18] discusses the influence of dead-time on inverter characteristics. It is addressed how to correct for dead time in asynchronous motor drives. The disturbance voltage generated by non-ideal inverter effects is utilized to determine the dead time compensation voltage (DTCV) amplitude. The adaptive DTCV minimizes the error between theoretical and actual power, according to the findings of the experiments.

\section{B. Volt/Hz Control and MPPT}

The study provided by Muljadi's [19] demonstrates a photovoltaic (PV) water pumping system utilized in agriculture and households. This method is quite popular in remote locations since it makes use of solar energy, which is widely exists all around the world. This system includes water pump, asynchronous motor, PV array and a variable speed inverter based on V/f control strategy. The inverter operates at variable frequency, taking input from the PV array and feeding it to the asynchronous motor, which then varies the output of the pump by creating a six-step quasi-square wave. Because of the usage of a six-step square wave inverter, the inverter also functions as a peak power tracker, reducing the number of switches. The benefit of this system is that it protects the system in the event of a short circuit since the current is restricted to the top limit of the PV array current. This model presented in this research does not contain a battery module, which makes the system more effective because the pump uses the full produced power.

\section{Field Oriented Control Algorithm}

The work proposed by Yulin Zhang et [20] at "Asynchronous motor control system based on FOC algorithm." This control depends on designs which change a 
three phase time and speed subordinate framework into a two coordinate ( $\mathrm{d}$ and $\mathrm{q}$ coordinates) time independent reference. These designs result in a control framework similar to that of a DC machine. Field oriented controlled machines need two constants as information references: the torque component (lined up with the q co-ordinate) and the transition component (lined up with d coordinate). As Field Orientated Control is just founded on designs the control structure handles prompt electrical amounts. That leads the control to be precise in each working operation (transient and steady state) and free of the constrained data transmission scientific model.

\section{DESIGN OF THE SUgGESTED SYSTEM}

The proposed system for a $5 \mathrm{kWatt}$ PV fed system is shown in Fig. 1. It is made up of a $4.5 \mathrm{HP}$ asynchronous motor connected to constant load (0N.m, 50N.m, 100N.m). The system is intended to be energized by a solar PV system. The asynchronous motor is powered by a three-phase voltage source inverter. During transient circumstances such as changing radiation, a DC link capacitor is used to reduce the ripple. As the Solar energy will produce a constant maximum power under its irradiance because of using MPPT driver which track the maximum power whatever the value of the load, there will be an extra DC power so it's recommended to be connected to AC Grid of 400V and 40MVAsc through AC 12 pulse 3 level grid connected inverter.

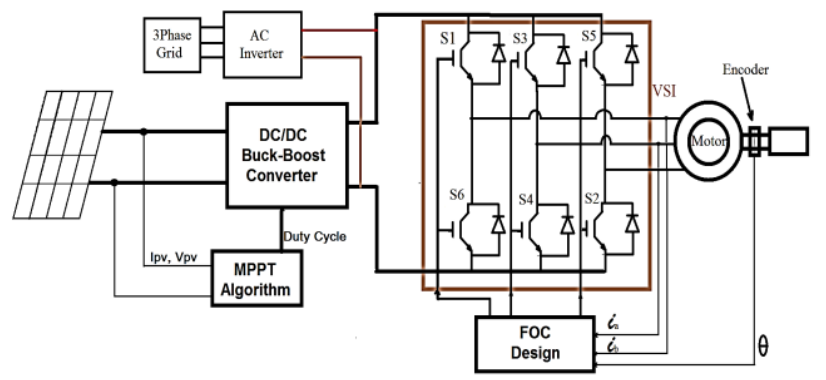

Fig. 1. Suggested Motor system fed by PV

\section{Field Oriented Control Algorithm}

This control is based on designs that convert the speed and three-phase time subordinate structure into a two different dimensional ( $\mathrm{q}$ and $\mathrm{d}$ coordinates) as time independent reference. These designs results in a framework like that of a DC machine control. As information references, field oriented controlled machines require two components: the torque component (lined up with the q coordinate) and the transition component (lined up with d coordinate). As Field Orientated Control is just founded on designs the control structure handles prompt electrical amounts. This makes the control precise in each working operation (transient and steady state) and free of the constrained data transmission scientific model. The Field Oriented Control eliminates the old scheme problems, in the following ways:

- The simplicity of approaching constant reference (flux component and torque component of the stator current)
- The simplicity of achieving direct torque control as in the (q, d) framework, the expression of the torque is:

$T=\psi_{R} * I_{q s}$

By keeping the value of the rotor flux $\left(\psi_{R}\right)$ at a fixed value Noticed that the developed torque is direct proportional to the torque current component $\left(I_{q s}\right)$. The developed torque can be then control by controlling the input value of the torque current component of stator current vector [21].

\section{SYSTEM OVERVIEW}

This case study shows a variable speed drive for asynchronous motor by using Field Oriented Control. In this control sketch, a $(\mathrm{d}, \mathrm{q})$ coordinates reference frame locked to the rotor flux space vector is utilized to achieve decoupling between the motor flux and torque. As in a DC motor, they can be regulated individually by stator direct current and quadrature current. This below Fig. 2 shows a block diagram of a Field Oriented Control drive for the three phase induction motor.

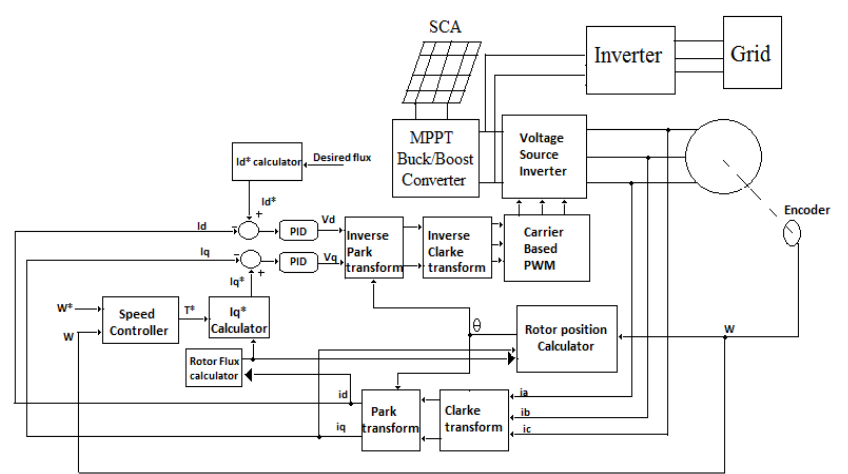

Fig. 2. Field-Oriented Variable-Frequency Induction Motor Drive.

The induction motor is fed by a voltage source inverter (VSI) controlled by Carrier Based PWM. The motor speed $\omega$ is compared to the reference speed $\omega^{*}$ and the error is processed by the speed controller to produce a torque command $T_{e}^{*}$

\subsection{Clarke Transform}

The space vector can be represented in another reference frame with only two perpendicular axis called $(\alpha, \beta)$. Assuming that the axis "a" and the axis " $\alpha$ " are in the same direction we have the following vector diagram:

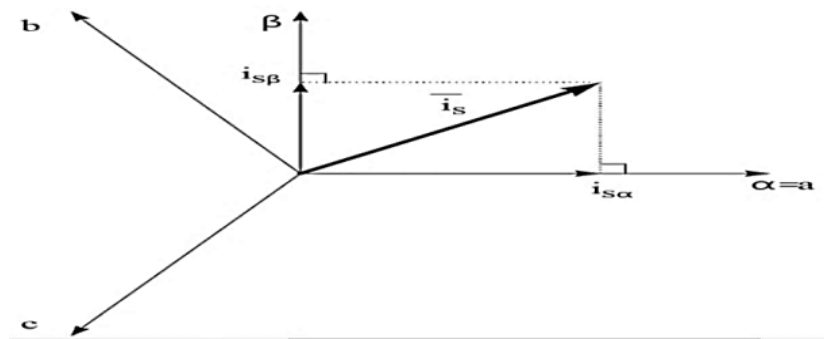

Fig. 3. Stator space vector current and its components in $(\alpha, \beta)$. 
The projection that modifies the three phase system into the $(\alpha, \beta)$ two orthogonal dimension system is presented below:

$i_{s \alpha}=\frac{3}{2} i_{s a}$

$i_{s \beta}=\frac{\sqrt{3}}{2} i_{s b}-\frac{\sqrt{3}}{2} i_{s c}$

We obtain a two coordinate system $i_{s \alpha} \quad, i_{s \beta}$ which is still based on time and speed.

\subsection{Park Transform}

This is the most essential transformation in the Field Oriented Control. In fact, this projection changes a two phase perpendicular system $(\alpha, \beta)$ in the $(\mathrm{d}, \mathrm{q})$ rotating reference frame. If we consider the $\mathrm{d}$ axis lined up with the rotor flux, the next diagram shows, for the current vector, the relationship from the two reference frame:

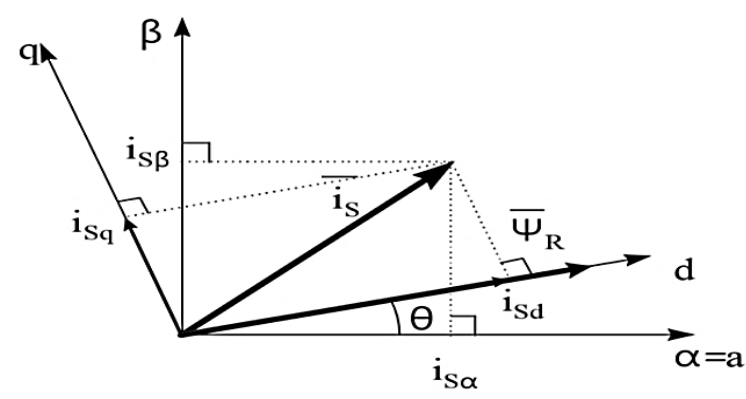

Fig. 4. Stator space vector current and its components in $(\alpha, \beta)$ and in the $d, q$ rotating reference frame with angle $\theta$.

Where, $\theta$ is the rotor flux position. The flux and torque components of the current vector are determined by the following equations:

$i_{s d}=i_{s \alpha} \cos \theta+i_{s \beta} \sin \theta$

$i_{s q}=-i_{s \alpha} \sin \theta+i_{s \beta} \cos \theta$

These components rely on the current vector $(\alpha, \beta)$ components and on the rotor flux position; if we know the exact rotor flux position then, by this projection, the $d, q$ components can be estimated.

We obtain a two co-ordinate system with the following characteristics:

- Two co-ordinates don't depend on time.

- With $i_{d s}$ (flux component) and $i_{q s}$ (torque component) the direct torque control is possible and simple.

\subsection{Flux Estimator}

This element is used to calculate the rotor flux in the motor. This calculation depends on motor equation synthesis [10].

$\psi_{R}=L_{m} * \frac{I_{d s}}{1+T_{r}}$

\subsection{Rotor Flux Position Estimator}

This element is used to estimate the exact position of rotor field using the following equations, $\theta_{f}=\theta_{r}+\theta_{m}$

$\omega_{f}=\int \theta_{r}+\theta_{m} d t$

\subsection{Carrier Based Pwm}

The most generally utilized strategy for pulse width modulation is performed. This technique is otherwise called the sinusoidal (SPWM), triangulation, sub-harmonic, or suboscillation strategy $[11,12]$. Sinusoidal adjustment depends on triangular transporter signal as appeared in Fig. 5. In this technique three reference signals UAc, UBc, UCc are compared with triangular bearer signal Ut, which is common to every one of the three phases. Along these lines the coherent sign SA, SB, SC are created, which characterize the exchanging moments of the power transistors as is appeared in Fig. 6.

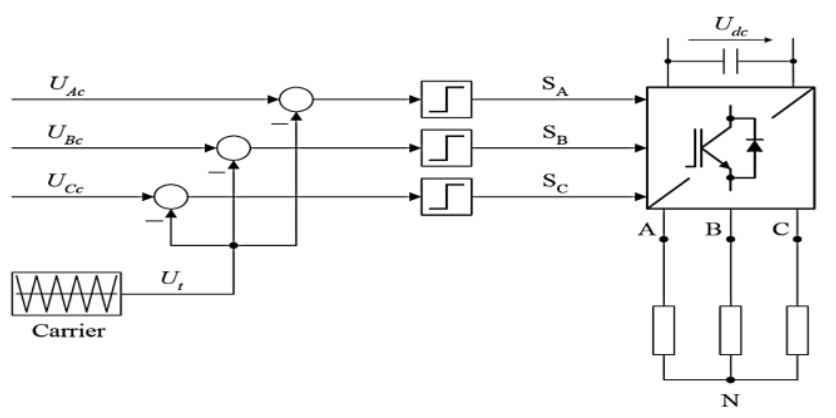

Fig. 5. Block diagram scheme for carrier based sinusoidal PWM.

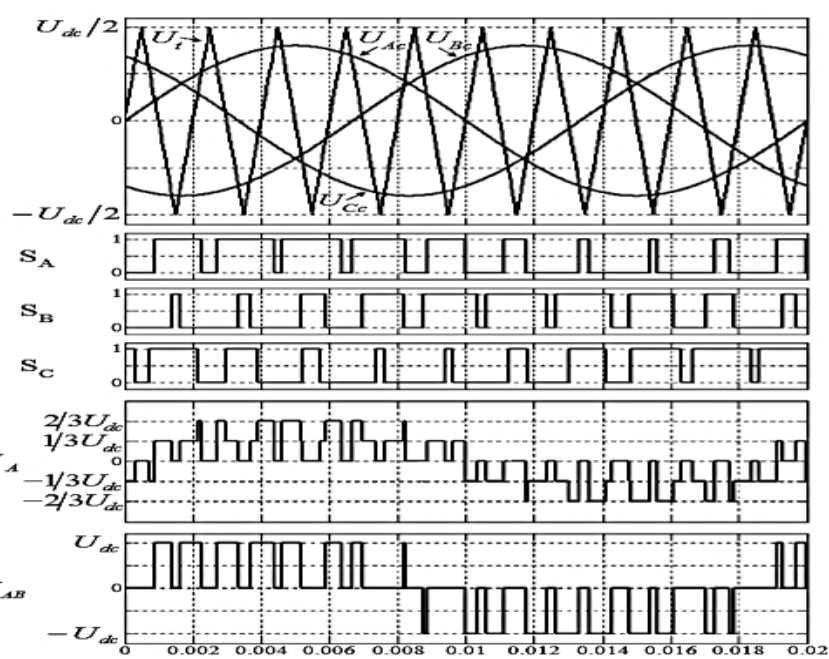

Fig. 6. Basic waveforms of carrier based sinusoidal PWM

\subsection{Speed Controller}

The control law used for this strategy is given by,

$T=K p * e+K i * \int e d t$

$e=\omega^{*}-\omega$

Its output is regulated by $\mathrm{PI}$ controller gains ( $\mathrm{Kp}$ and $\mathrm{Ki}$ ) based on a set of rules to maintain excellent control performance even in the existence of parameter variation and drive nonlinearity. At starting mode the high value of the error is amplified across the PI controller provoking high variations in the desired torque. If $\mathrm{Kp}$ and $\mathrm{Ki}$ of the PI controller exceed 
a certain value, the changes in the desired torque become too high and will destabilize the system. To override this problem, a limiter placed after the PI controller is used. When properly set, this limiter causes the speed error to be kept within limits, resulting in smooth fluctuations in the required torque even when the PI controller gains are quite large [20-23]. The Simulink model of PI controller is designed as shown in Fig. 5. The model is formed with gain coefficients $\mathrm{Kp}$ and $\mathrm{Ki}$ tuned at 40 and 50 respectively. The motor to be controlled is in a closed loop with the FOC block, which creates inverter switching signals to achieve the motor's target speed.

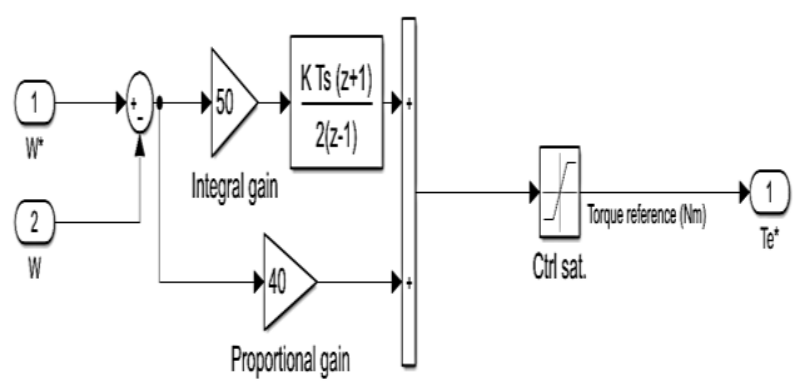

Fig. 7. Simulink models of conventional PI speed controller

\section{MPPT TECHNIQUES}

\section{A. Perturb \& Observe}

The perturb and observe approach has been widely utilized as it is simple to implement. The $\mathrm{P} \& \mathrm{O}$ technique directs the PV system to reach the MPP by raising or reducing output voltage of the PV panel. A DC/DC converter is installed between the solar panel and the load to adjust the voltage of the PV panel. The duty cycle of the converter is adjusted to change the voltage of the PV panels. As its name implies, $\mathrm{P} \& \mathrm{O}$ method performs perturbation of $\mathrm{Vpv}$ and observe of its effect on the change of the output power of panel statement by changing duty cycle (D) of the converter. The control flow chart for the $\mathrm{P} \& \mathrm{O}$ technique is shown in Fig. 8, where $\mathrm{k}$ is an integer value $1,2,3, \ldots \ldots$.

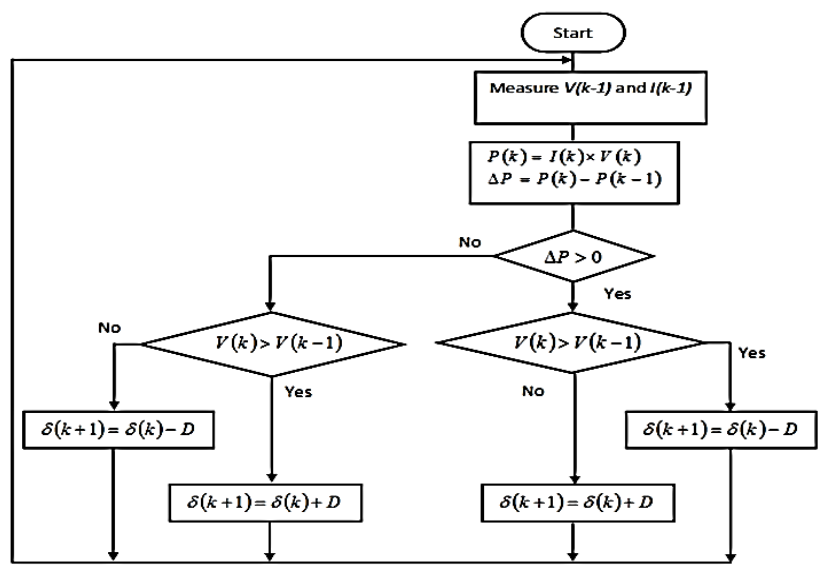

Fig. 8. Flowchart of the $\mathrm{P} \& \mathrm{O}$ algorithm

\section{B. Incremental Conductance}

The P-V characteristic curve was used to create Incremental Conductance. This method was created in 1993 to address some of the limitations of the $\mathrm{P} \& \mathrm{O}$ algorithm. The incremental conductance technique is regarded as one of the most effective ways for tracking module MPP. Maximum power point is determined using the rate of change of power with respect to voltage $(d P / d V)$. Along with the above derivative, the relation between $\frac{d I}{d V} \&-\frac{I}{V}$ is an important factor in the incremental conductance methodology (InC) attempts to enhance the tracking time and produce more energy in a changing environment due to irradiation [3]. By using the relation between $d I / d V$ and $-I / V$, the MPP can be easily estimated. If $d P / d V$ is negative then MPP is lies to the right of the most recent position and if it's positive, the MPP is on the left of the most recent position [15], [25-26]. The equations of Inc. method is:

$\frac{d I}{d V}=-\frac{I}{V} \quad$ Module power is at MPP

$\frac{d I}{d V}<-\frac{I}{V} \quad$ Module power is Right of MPP

$\frac{d I}{d V}>-\frac{I}{V} \quad$ Module power is left of MPP

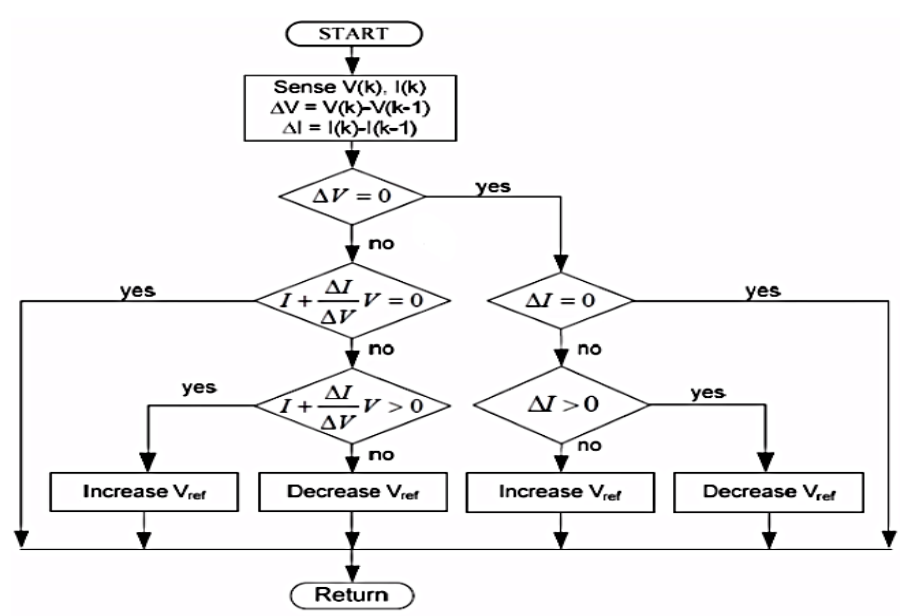

Fig. 9. Flowchart of the InC. algorithm

\section{SimulinK MODEL}

Fig. 10 shows the Simulink model of a Field Oriented Control drive for the three phases, 4.5 HP, $460 \mathrm{~V}$, Two-pole, $60 \mathrm{~Hz}$ Asynchronous motor fed from 5 kwatt solar cell array (SCA). 


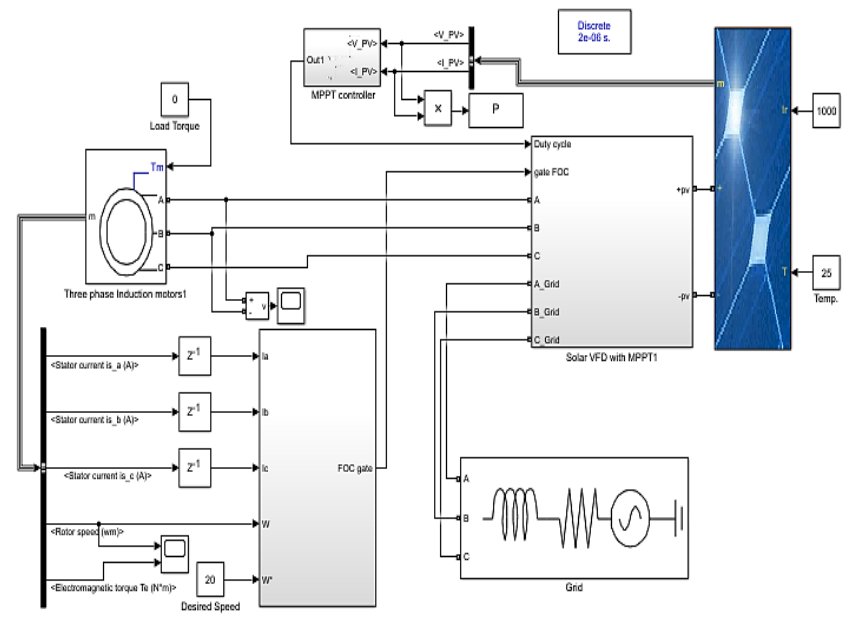

Fig. 10. Simulink model of speed controller system for Squirrel cage Asynchronous Motor (SCIM).

Fig. 11 shows the PV module characteristic curves under $100 \mathrm{~W} / \mathrm{m}^{2}, 500 \mathrm{~W} / \mathrm{m}^{2}$ and $1000 \mathrm{~W} / \mathrm{m}^{2}$.

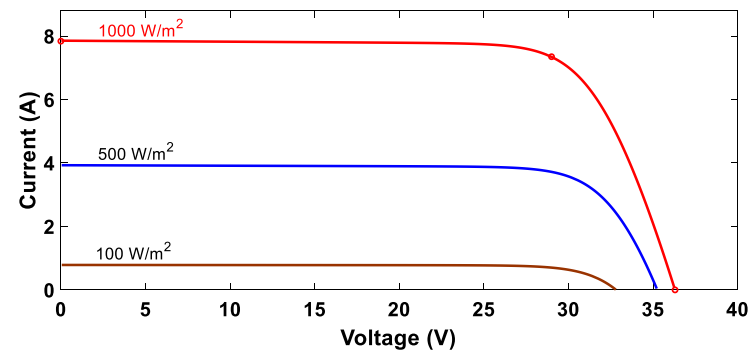

(a)

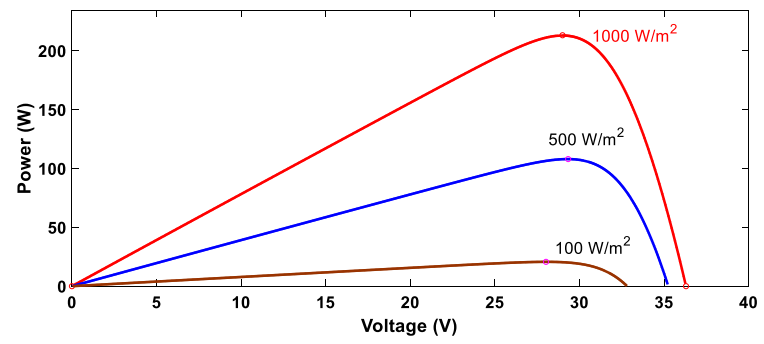

(b)

Fig. 11. PV Solar module at $1000 \mathrm{~W} / \mathrm{m} 2,500 \mathrm{~W} / \mathrm{m} 2$ and $100 \mathrm{~W} / \mathrm{m} 2$.
(a) I-V curve,
(b) P-V curve.

\section{Simulation RESUltS}

To simulate the machine in Simulink, the Simulink model first has to be initialized so that it will get all the machine parameters. The Asynchronous motor used here is $4.5 \mathrm{HP}, 460$ $\mathrm{V}$, Two-pole, $60 \mathrm{~Hz}$ motor. The speed has been noticed for 4 sec for each model. The solar irradiance applied on PV solar array is described in Fig. 12. The irradiance has been reduced in time equal to $2 \mathrm{sec}$. The results of output speed at no load by using Incremental Conductance and Perturb \& observe algorithms with Proportional Integral Speed controller based on Field Oriented Control algorithm are shown in Fig. 13.

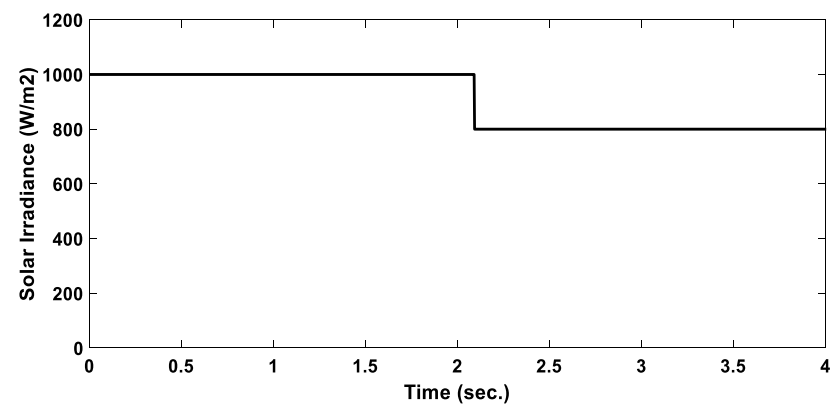

Fig. 12. Simulation of the motor speed for the reference speed $20 \mathrm{rad} / \mathrm{s}$ and no-load.

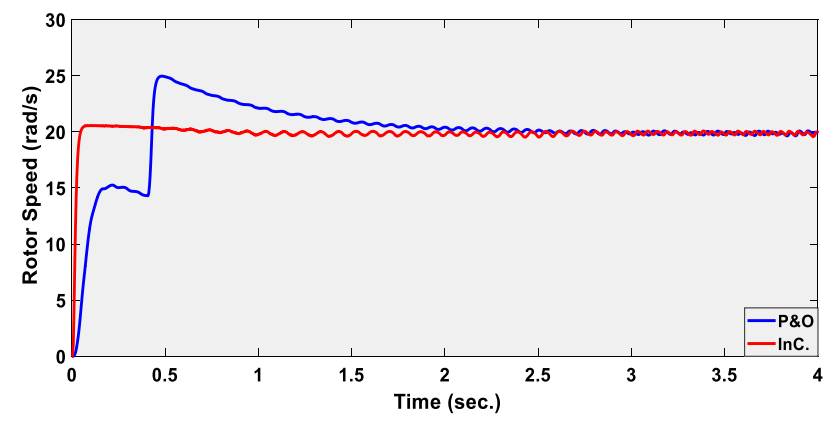

Fig. 13. Simulation of the motor speed for the reference speed $20 \mathrm{rad} / \mathrm{s}$ and no-load.

Fig. 14 shows how the incremental conductance technique will result in faster torque response at the transient state but it has nearly more than twice the overshoot torque of the $\mathrm{P} \& \mathrm{O}$ technique. This will cause lower settling time and faster speed response.

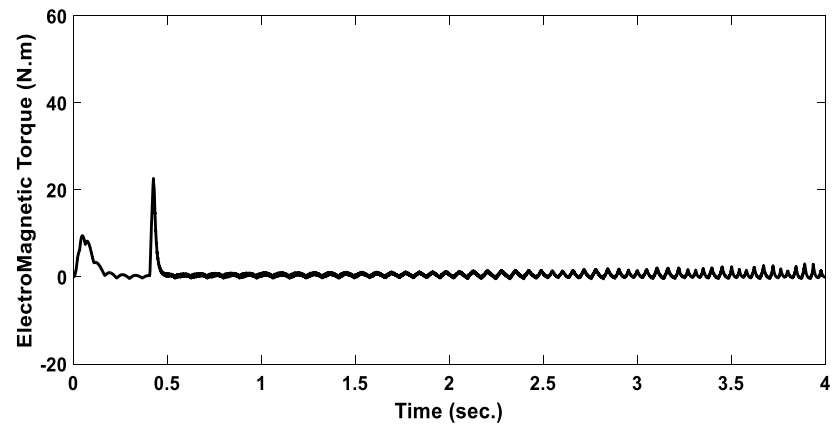

(a)

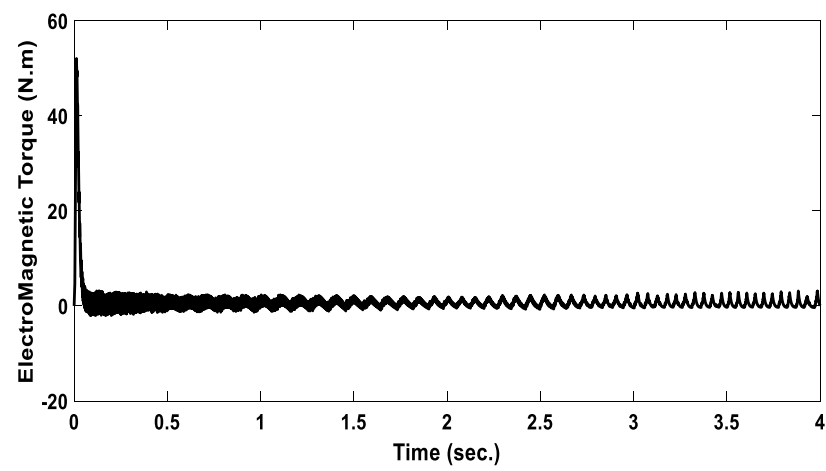

(b)

Fig. 14. Torque simulation for the reference speed $20 \mathrm{rad} / \mathrm{s}$ and no load. (a) Perturb \& Observe, (b) Incremental Conductance. 
Fig. 15 shows the produced DC power of the buck-boost converter. It's noticed that incremental conductance has faster rising time for the $\mathrm{DC}$ power than the $\mathrm{P} \& \mathrm{O}$. $\mathrm{P} \& \mathrm{O}$ technique has higher steady state ripple as compared to incremental conductance. At time equal to $2 \mathrm{sec}$, when the solar irradiance has been reduced from $1000 \mathrm{~W} / \mathrm{m}^{2}$ to $800 \mathrm{~W} / \mathrm{m}^{2}$, the DC power will be reduced from $4.5 \mathrm{kw}$ to $3.6 \mathrm{kw}$ and there is transient small ripple spike in $\mathrm{DC}$ power in case of $\mathrm{P} \& \mathrm{O}$ technique.

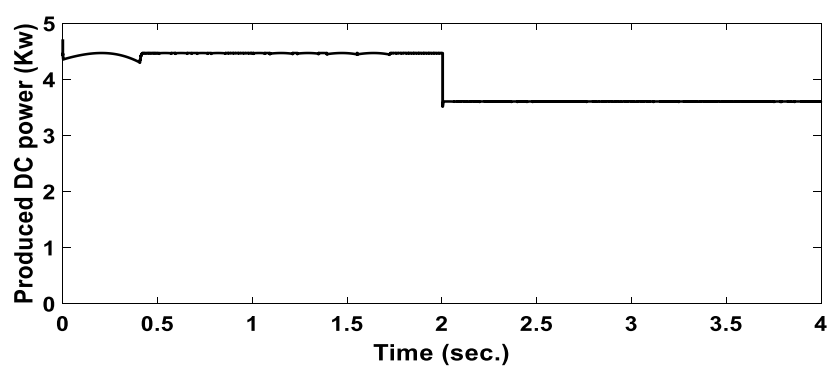

(a)

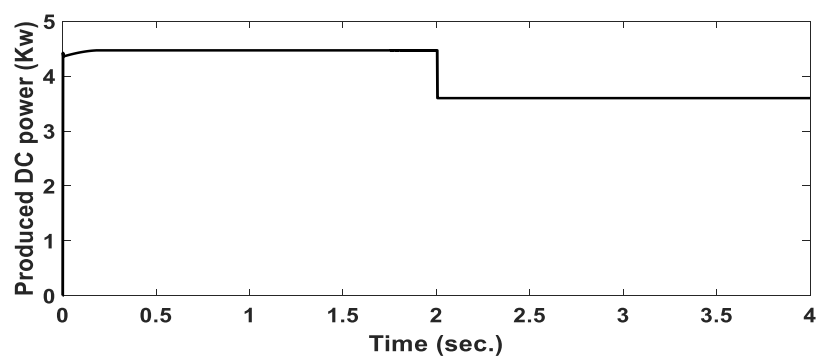

(b)

Fig. 15. Produced DC power of DC/DC buck boost converter simulation for the reference speed $20 \mathrm{rad} / \mathrm{s}$ and no load.

(a) Perturb \& Observe, (b) Incremental Conductance.

It's noticed that transmitted power to the grid in case of incremental conductance has faster settling time as compared to that of $\mathrm{P} \& \mathrm{O}$ as shown in Fig. 16. $\mathrm{P} \& \mathrm{O}$ technique has higher steady state ripple as compared to incremental conductance. At time equal to $2 \mathrm{sec}$, when the solar irradiance has been reduced from $1000 \mathrm{~W} / \mathrm{m}^{2}$ to $800 \mathrm{~W} / \mathrm{m}^{2}$, the DC power will be reduced from $4.5 \mathrm{kw}$ to $3.6 \mathrm{kw}$ and there is transient small ripple spike in DC power in case of $\mathrm{P} \& \mathrm{O}$ technique.

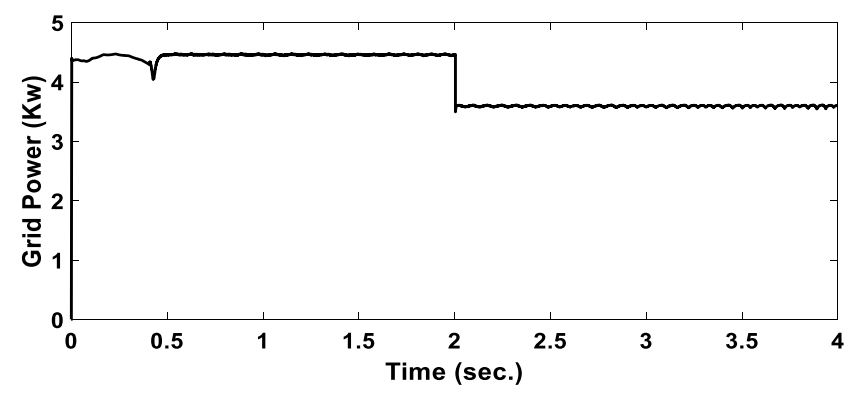

(a)

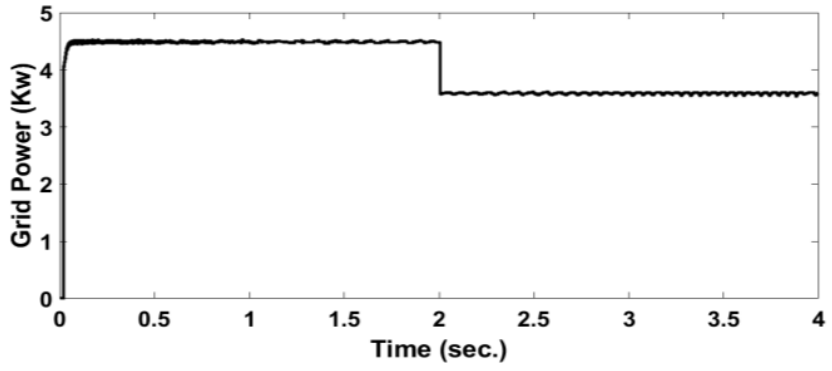

(b)

Fig. 16. Grid transmitted power simulation for the reference speed $20 \mathrm{rad} / \mathrm{s}$ and no load. (a) Perturb \& Observe, (b) Incremental Conductance.

It's noticed that DC link voltage of the system using incremental conductance has faster rising time than the system using $\mathrm{P} \& \mathrm{O}$ as shown in Fig. 17. $\mathrm{P} \& \mathrm{O}$ technique has higher steady state ripple as compared to incremental conductance. At time equal to $2 \mathrm{sec}$, the DC voltage stayed constant as $496 \mathrm{~V}$ but there is transient small ripple spike in DC voltage in case of $\mathrm{P} \& \mathrm{O}$ technique, when the solar irradiance has been reduced from $1000 \mathrm{~W} / \mathrm{m}^{2}$ to $800 \mathrm{~W} / \mathrm{m}^{2}$.

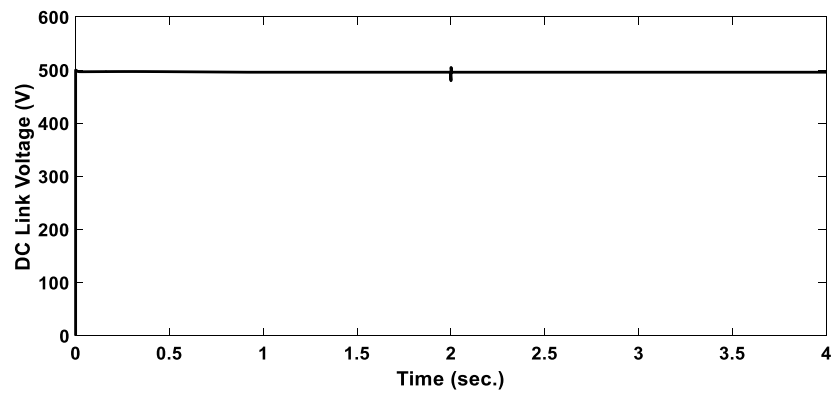

(a)

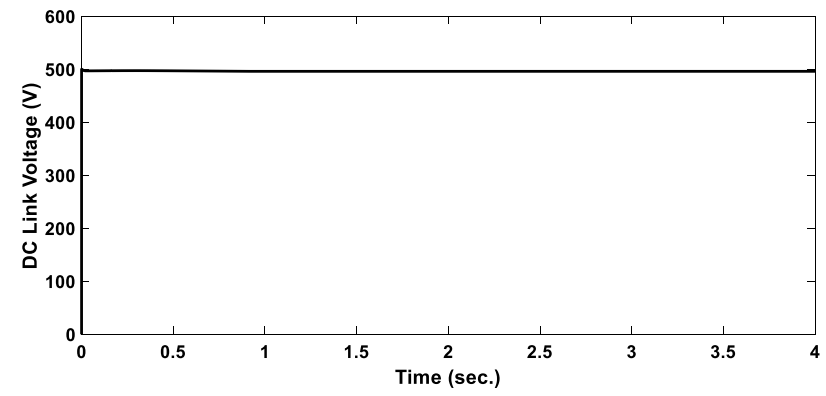

(b)

Fig. 17. DC Link Voltage simulation for the reference speed $20 \mathrm{rad} / \mathrm{s}$ and no load. (a) Perturb \& Observe, (b) Incremental Conductance.

Fig. 18 shows how the incremental conductance has higher inrush transient current as compared to $\mathrm{P} \& \mathrm{O}$ technique but InC. is much faster for reaching steady-state than that of the $\mathrm{P} \& \mathrm{O}$ technique. That's because of the slow rising time of $\mathrm{P} \& \mathrm{O}$ as compared to $\mathrm{InC}$. 


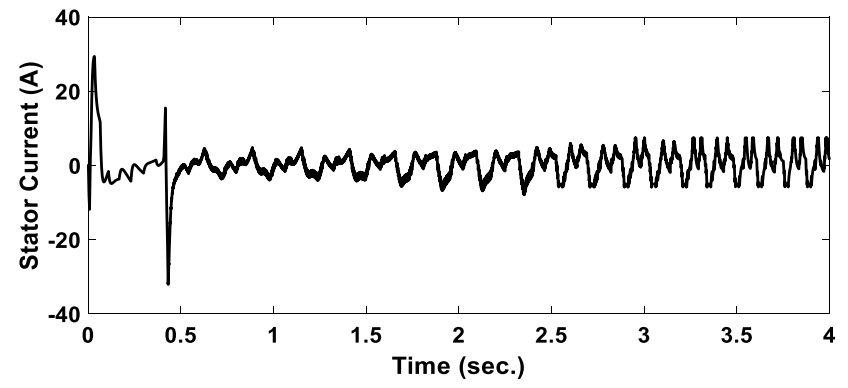

(a)

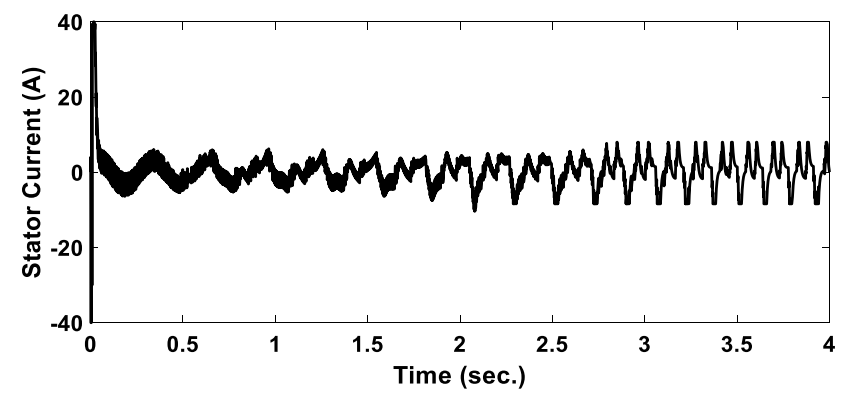

(b)

Fig. 18. Stator Current simulation for the reference speed $20 \mathrm{rad} / \mathrm{s}$ and no load. (a) Perturb \& Observe, (b) Incremental Conductance.

The dynamic performance analysis with increasing the mechanical load (0N.m, 50N.m and 100N.m) value is described in TABLE I. TABLE I shows that the incremental conductance is much better at higher load as the steady state error for incremental conductance technique is lower than the one of perturb \& observe technique at higher load torque.

TABLE I

UNITS FOR MAGNETIC PROPERTIES

\begin{tabular}{|c|c|c|c|}
\hline $\begin{array}{c}\text { At } \\
\text { Load } \\
\text { (N.m) } \\
\end{array}$ & METHOD & $\begin{array}{l}\text { Rising Time } \\
\quad \operatorname{Tr}(\mathrm{ms})\end{array}$ & $\begin{array}{c}\text { Overshoot } \\
\text { peak } \\
(\operatorname{Rad} / \mathbf{s}) \\
\end{array}$ \\
\hline \multirow{2}{*}{0} & $\mathrm{P} \& \mathrm{O}$ & 388.355 & 4.97 \\
\hline & InC. & 24.414 & 2.14 \\
\hline \multirow{2}{*}{50} & $\mathrm{P} \& \mathrm{O}$ & 450.335 & 3.64 \\
\hline & InC. & 25.153 & 2.01 \\
\hline \multirow{2}{*}{100} & $\mathrm{P} \& \mathrm{O}$ & 500.300 & 2.83 \\
\hline & InC. & 25.994 & 1.05 \\
\hline
\end{tabular}

\section{Conclusion}

MATLAB/Simulink was used to create a mathematical model of a $5 \mathrm{KW}$ solar panel in this research. This model is used to achieve the maximum power of the PV solar array by using two different techniques. The speed control of the Asynchronous motor for industrial application is achieved by using very brand new technique (Field Oriented Control) to adjust the motor speed based on speed error, and the power of PV solar system power is regulated by two different techniques (Incremental Conductance and Perturb \& Observe). Incremental Conductance and Perturb \& Observe MPPT techniques are reviewed, as well as their simulation results. At time equal to $2 \mathrm{sec}$, when the solar irradiance has been reduced from $1000 \mathrm{~W} / \mathrm{m}^{2}$ to $800 \mathrm{~W} / \mathrm{m}^{2}$, the DC voltage stayed constant as $496 \mathrm{~V}$ and DC power drops from $4.5 \mathrm{kw}$ to $3.6 \mathrm{kw}$ but there is transient small ripple spike in DC power in case of $\mathrm{P} \& \mathrm{O}$ technique. It has been demonstrated that the Incremental conductance technique outperforms the $\mathrm{P} \& \mathrm{O}$ algorithm. These techniques increase the solar system's dynamics and steadystate performance, as well as the effectiveness of the DC-DC converter system. From this work, it can be inferred that for rural areas where there is no electricity, the PV provided Asynchronous motor framework may be introduced to meet the need for water for irrigation or any industrial application of Asynchronous motor. The PV-fed Asynchronous motor using the control approaches presented in this work may be regarded an efficient system since it provides decoupling between flux and torque control as well as direct flux control for the asynchronous motor using field oriented control technique.

\section{APPENDIX}

TABLE II shows the specification parameter for both asynchronous motor and PI speed controller.

TABLE II

SPECIFICATIONS OF ASYNCHRONOUS MOTOR \& CONTROLLER

\begin{tabular}{|c|c|}
\hline \multicolumn{2}{|c|}{ Asynchronous motor } \\
\hline Motor type & $4.5 \mathrm{HP}, 460 \mathrm{~V}, 60 \mathrm{~Hz}$ \\
\hline Stator Resistance, $R_{S}$ & $0.6837 \mathrm{ohm}$ \\
\hline Rotor Resistance, $R_{r}$ & $0.451 \mathrm{ohm}$ \\
\hline Stator inductance, $L_{S}$ & $0.004152 \mathrm{H}$ \\
\hline Rotor inductance, $L_{r}$ & $0.004152 \mathrm{H}$ \\
\hline Mutual inductance, $L_{m}$ & $0.1486 \mathrm{H}$ \\
\hline Inertia, $J$ & $0.05 \mathrm{Kg} \cdot \mathrm{m}^{2}$ \\
\hline No of poles & 2 \\
\hline \multicolumn{2}{|c|}{ PI speed controller } \\
\hline Proportional gain, $P$ & 40 \\
\hline Integral gain, I & 50 \\
\hline \multicolumn{2}{|c|}{ Solar Array } \\
\hline No. of parallel strings & 2 \\
\hline No. of series modules & 15 \\
\hline Maximum system power & $5 \mathrm{kw}$ \\
\hline Module Maximum Power & 213.15 \\
\hline $\begin{array}{l}\text { Module open circuit } \\
\text { voltage }\end{array}$ & $36.3 \mathrm{~V}$ \\
\hline $\begin{array}{l}\text { Module Short circuit } \\
\text { voltage }\end{array}$ & $7.84 \mathrm{~A}$ \\
\hline
\end{tabular}

\section{AUTHORS CONTRIBUTION}

Solar variable speed asynchronous motor drive based on maximum power tracking field oriented control is implemented with Matlab/Simulink. The proposed paper shows the effect of two different techniques on field oriented control speed drive for asynchronous motor.

Ahmed M. Ismaiel is responsible for design and analysis the propose system.

Basem E. Elnaghi is responsible for drafting the article.

Reham H.Mohammed is responsible for investigating the difference between Perturb and Observe and Incremental Conductance. 


\section{FUNDING STATEMENT:}

The author did not receive any financial support of the research authorship and publication of this article

\section{DECLARATION OF CONFLICTING INTERESTS STATEMENT:}

The author declared that there are no potential conflicts of interest with respect to the research authorship or publication of this article

\section{REFERENCES}

[1] Neymark, Joel, and Ron Judkoff. "International energy agency building energy simulation test and diagnostic method for heating, ventilating, and air-conditioning equipment models (HVAC BESTEST)"; Volume 1: Cases E100-E200. No. NREL/TP-550-30152. National Renewable Energy Lab., Golden, CO.(US), 2002.

[2] Halcrow, Sir William. "Small-scale solar powered irrigation pumping systems: technical \& economic review". World Bank (1818 H Street, NW, Washington DC 20433), 1981.

[3] Philip, Jincy, et al. "Control and implementation of a standalone solar photovoltaic hybrid system." IEEE Transactions on Industry Applications 52.4 (2016): 3472-3479.

[4] An, Le, and Dylan Dah-Chuan Lu. "Design of a single-switch DC/DC converter for a PV-battery-powered pump system with PFM+ PWM control." IEEE Transactions on Industrial Electronics 62.2 (2014): 910921.

[5] Jain, Sachin, et al. "Dual MPPT algorithm for dual PV source fed openend winding Asynchronous motor drive for pumping application." Engineering Science and Technology, an International Journal 19.4 (2016): 1771-1780.

[6] Pires, Vitor, et al. "A grid connected photovoltaic system with a multilevel inverter and a Le-Blanc transformer." International Journal of Renewable Energy Research (IJRER) 2.1 (2012): 84-91.

[7] Patnaik, B., et al. "Reconfiguration strategy for optimization of solar photovoltaic array under non-uniform illumination conditions." 2011 37th IEEE Photovoltaic Specialists Conference. IEEE, 2011.

[8] Korpale, V. S., D. H. Kokate, and S. P. Deshmukh. "Performance assessment of solar agricultural water pumping system." Energy Procedia 90 (2016): 518-524

[9] Gupta, Mukesh, Shivani Johri, and Gaurav Kumar Chaturvedi. "Implementation of high efficiency, high lifetime and low cost converter for an automatic photovoltaic water pumping station." International Journal of Advanced Engineering Research and Science 3.8 (2016): 236823.

[10] Nazeer, Najna, and T. N. Shahina. "Speed Control For Indirect Vector Control Of Induction Motor Drives At Low Speeds." 2019 2nd International Conference on Intelligent Computing, Instrumentation and Control Technologies (ICICICT). Vol. 1. IEEE, 2019.

[11] Bose, Bimal K. Modern power electronics and AC drives. Vol. 123. Upper Saddle River, NJ: Prentice hall, 2002.

[12] Holtz, Joachim. "Pulsewidth modulation for electronic power conversion." Proceedings of the IEEE 82.8 (1994): 1194-1214.

[13] Ramulu, Chinthamalla, et al. "A solar PV water pumping solution using a three-level cascaded inverter connected Asynchronous motor drive." Engineering Science and Technology, an International Journal 19.4 (2016): 1731-1741.

[14] Attique, Qamar Muhammad, Yongdong Li, and Kui Wang. "A survey on space-vector pulse width modulation for multilevel inverters." CPSS Transactions on Power Electronics and Applications 2.3 (2017): 226236.

[15] Holtz, Joachim. "Pulsewidth modulation for electronic power conversion." Proceedings of the IEEE 82.8 (1994): 1194-1214.

[16] Narayanan, G. "Synchronised pulsewidth modulation strategies based on space vector approach for Asynchronous motor drives." (2005).
[17] Venugopal, S. Study On Overmodulation Methods For PWM Inverter Fed AC Drives. Diss. Indian Institute of Science, 2007.

[18] Urasaki, Naomitsu, et al. "On-line dead-time compensation method for voltage source inverter fed motor drives." Nineteenth Annual IEEE Applied Power Electronics Conference and Exposition, 2004. APEC'04. Vol. 1. IEEE, 2004.

[19] Muljadi, Eduard. "PV water pumping with a peak power tracker using a simple six-step square-wave inverter." IEEE Transactions on industry applications 33.3 (1997): 714-721.

[20] $\mathrm{Li}$, Wei, Zhifeng Xu, and Yulin Zhang. "Asynchronous motor control system based on FOC algorithm." 2019 IEEE 8th Joint International Information Technology and Artificial Intelligence Conference (ITAIC). IEEE, 2019.

[21]Lee, Jae Suk, et al. "Deadbeat direct torque and flux control of interior permanent magnet synchronous machines with discrete time stator current and stator flux linkage observer." IEEE Transactions on Industry Applications 47.4 (2011): 1749-1758.

[22] Ji, Deming, et al. "Design of Induction Motor Vector Control Variable Frequency Speed Regulation System Based on DSP." Electronic Science \& Technology 3 (2016): 10

[23] Massaq, Zakaria, et al. "Double Stage Solar PV Array Fed Sensorless Vector Controlled Induction Motor for Irrigational Purpose." 2019 7th International Renewable and Sustainable Energy Conference (IRSEC). IEEE, 2019

[24] Shukla, Saurabh, and Bhim Singh. "Single-Stage PV-Grid Interactive Induction Motor Drive with Improved Flux Estimation Technique for Water Pumping With Reduced Sensors." IEEE Transactions on Power Electronics 35.12 (2020): 12988-12999.

[25] Sharma, Apoorva, Tripurari Nath Gupta, and Mahiraj Singh Rawat. "Grid Connected Solar PV fed Constant Power Water Pumping System." 2021 International Conference on Intelligent Technologies (CONIT). IEEE, 2021.

[26] Kumari, Rajni, and Ratna Dahiya. "Speed control of solar water pumping with indirect vector control technique." 2018 2nd International Conference on Inventive Systems and Control (ICISC). IEEE, 2018.

Title in Arabic:

مغيرات السرعة المتقدمة لمحركات الغير متزامنة ثلاثي الأطوار

\section{Abstract in Arabic:}

في هذا العمل ، يتم استخدام الطاقة الثمسية بكفاءة عن طريق تشغيل الألواح

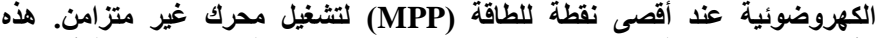

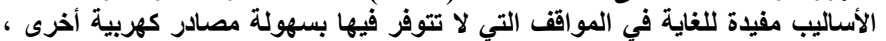

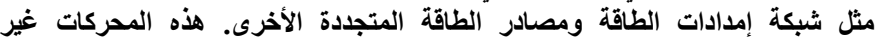

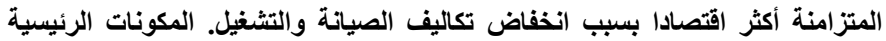

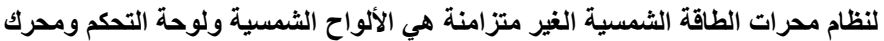

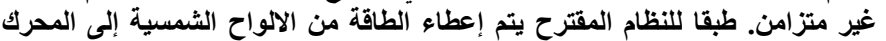

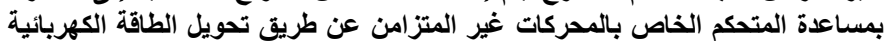

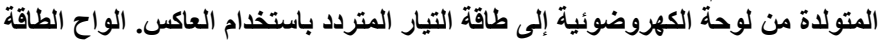

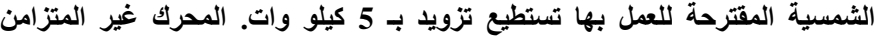

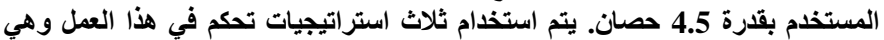
تعديل Field Oriented و (PWM) Carrier Pulse width modulation (FOC) Control

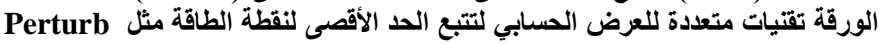
Field ب استخدام (Incremental Conductance (Inc) \& Observe (P\&O) Matlab / Simulink بتم تنفيذ تقتيات التحكم باستخدام Oriented Control

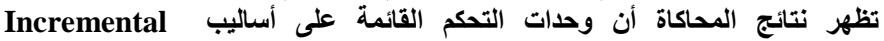
لمع Conductance لأن لها قيمة تجاوز أصغر ، ووقت صعود أقصر ، واستجابة ديناميكية عالية. 